\title{
Perancangan Emergency Buttton Untuk Pendaki Gunung Dengan Sistem Komunikasi Multihop Berbasis LoRa
}

\author{
Gita Affrylia \\ Jurusan Teknik \\ Elektro,Program Studi Teknik \\ Telekomunikasi DIV \\ Politeknik Negeri Sriwijaya \\ Palembang, Indonesia \\ gita.affrylia20@gmail.com
}

\author{
Mohammad Fadhli \\ Jurusan Teknik Elektro, \\ Program Studi Teknik \\ Telekomunikasi DIV \\ Politeknik Negeri Sriwiijaya \\ Palembang, Indonesia \\ mohammad.fadhli@polsri.ac.id
}

\author{
Lindawati \\ Jurusan Teknik Elektro, \\ Program Studi Teknik \\ Telekomunikasi DIV \\ Politeknik Negeri Sriwijaya \\ Palembang, Indonesia \\ lindawati9111@yahoo.com
}

\begin{abstract}
Mountain is one of the tourist destination that are currently in great demand by various circles of society, specially for young people. This is evidenced by the increase in the mountaineering tourist visitour data that increase every years. The increase in public interest in mountaineering also leads to many cases of accidenct. That occur during mountainerring, such as the loss climbers in mountainousareas, the loss of climbers on mountain tracks, and other accidents that must immediately require emergency assistance. The difficult to find by giards and others search teams. Therefor, in this study we disigned an Eemergency Button tool for mountaineers designed to beable to perform the emergency call process when a person has an accident while in an inaccesible terrain such as mountains. It is integrated in the LoRa-based Multihop Communications System an Global Posiyioning System (GPS). Signals or data sently by climbers through the emergency button in the form of coordinate points of the location of climbers. The coordinates sent by the climbers will later be sent to the mountain guard post server which was previously via Relay, the coordinate data has been received will automatically be uploaded to thinkspeak so that it can be acces using the internet and converted into a google maps display from. It is hoped that this will make it easier to find the location of climbers accurately and quackly.
\end{abstract}

Keywords: GPS, Emergency Button, Multihop, and LoRa.

\section{PENDAHULUAN}

Aktivitas sehari-hari kehidupan manusia yang padat telah menyebabkan manusia mulai mencari hiburan di alam terbuka, salah satu trend yang sekarang ini mulai banyak digemari adalah mendaki gunung. Peminat utama dalam hal iniadalah kalangan remaja. Ini dibuktikan dengan banyaknya kelompok pendaki gunung yang mulai bermunculan. Selain untuk hiburan, ada banyak makna yang dimilikioleh setiap pendaki dalam melakukan pendakian [1]. Namun seiring dengan adanya peningkatan jumlah pendaki, kecelakaan yang terjadi pada pendakian gunung juga ikut mengalami peningkatan. Angka kecelakaan pada pendakian gunung pernah berada di angka 85 orang.

Ada banyak hal yang dapat menyebabkan pendaki mengalami kecelakaan, hipotermia merupakan salah satu dari banyaknya penyebab pendaki mengalami kecelakaan. Jumlah pendaki yang mengalami kecelakaan ini semakin meningkat di tahun 2019[2]. Oleh karena itu, menyadari perlu adanya upaya untuk menyelesaikan permasalahan di atas, penulis berupaya memberikan solusi dengan merancang sebuah alat Emergency Button bagi pendaki gunung yang menggunakan sistem komunikasi multihop dan berbasis LoRa.

Long Range atau yang biasa dikenal dengan sebutan LoRa merupakan sebuah teknologi jarak jauh tanpa kabel yang telah dipatenkan oleh Semtech dengan standar yang dimiliki adalah LoRa WAN. Teknologi Chrip Spread Spectrum (CSS) merupakan teknologiyang akhirnya menghasilkan teknik modulasi spread spectrum LoRa. Pengimplementasian LoRa telah diterapkan pada beberapa aspek kehidupan manusia, seperti smart city, smart home, dan lain sebagainya[3]. Namun, pada dasarnya jarak jangkaun yang dapat dilakukan olehLoRa hingga ia mendapatkandata hanya berada pada jarak kurang lebih $1 \mathrm{Km}$, terlebih lagi jika berada pada wilayah pegunungan yang banyak pepohonan semakin menyebabkanjarakjangkau an LoRa berkurang. Oleh karena itu, pada penelitian kali ini digunakan sistem komunikasi multihop dengan Relay sebagai jembatan penghubung antara Transmitter yang dalam hal ini adalah Emergency Button dengan Receiver (Pos Penjaga).

Sistem Komunikasi multihop merupakan komunikasi yang dapat digunakan untuk memperluas sebuah jaringan nirkabelagar efek buruk melemahnya suatu sinyal yang dialami oleh saluran nirkabel dapat diatasitanpa harus membutuhkan lebih banyak sumber daya jaringan sehingga komunikasi yang digunakan dengan node lain yang berada diluar jangkauannya masih dapat dilakukan dengan baik[4]. Dengandigunakannya sistem komunikasi multihop ini, diharapkan jarak jangkauan LoRa dapat berada 


\section{Perancangan Emergency Buttton Untuk Pendaki Gunung Dengan Sistem Komunikasi Multihop Berbasis LoRa}

pada jangkauan maksimal, serta dapat menurunkan tingkat kecelakaan pendaki.

\section{DASAR TEORI}

A. LoRa

Long Rang (LoRa) merupakan salah satu teknologi nirkabel yang beroperasi pada rentang $\mathrm{f}$ rekuensi 920- $923 \mathrm{MHz}$ yang telah ditetapkan oleh Peraturan Menteri Kominfo No.1 Tahun 2019 Tentang Penggunaan Spektrum Frekuensi Radio Berdasarkan Izin Kelas dan PERDIRJEN SDPPI No 3 Tahun 2019: LPWA Spesification[5]. Dengan itu, LoRa yang akan gunakan sebaiknya di-setting terlebih dahulu sesuai dengan peraturan frekuensi yang telah ada.

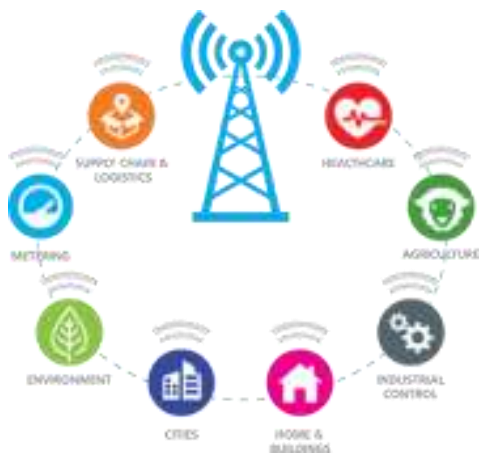

Gambar 1. Teknologi LoRa[3]

B. Arduino

Arduino merupakan sebuah platform elektronik yang bersifat open source yang menggunakan perangkat lunak Arduino IDE untuk dapat menjalankan perintah programnya. Dengan ini, arduino juga dapat diartikan dengan sebuahperangkat keras dan perangkat lunak yang tergabung menjadi 1. Dengan memasukkan berbagaiperintah program ke papan arduino melalui Arduino IDE, maka arduino tersebut dapat melakukan beberapa perintah yang diinginkan, seperti menghidupkan lampu, menghidupkan motor, dan hal menarik lainnya[7].

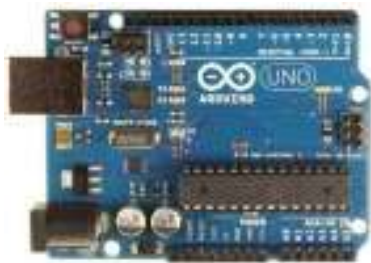

Gambar 2. Arduino Uno [8]

\section{ESP8266}

Selain menggunakan Arduino pada penelitian ini juga menggunakan ESP8266 yang berfungsi untuk mengupload data yang ada ke jaringan wifi.

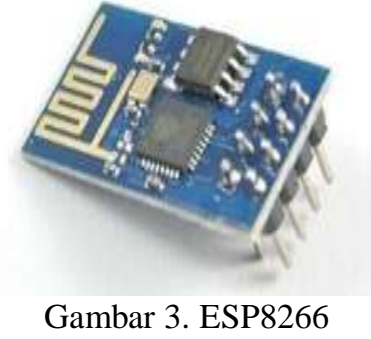

ESP8266 merupakan sebuah teknologi yang memungkin kita untuk dapat mengakses data ke jaringan Wi-Fi dengan menggunakan sebuah protocol TCP/IP. ESP8266 juga merupakan bagian dari sistem chip (SOC) dan jaringan Wi-Fi untuk perangkat lunak yang efektif untuk meng-host sebuah aplikasi atau menghapus semua fungsi pada jaringan Wi-Fi dari prosessor aplikasi. Untuk dapat meningkatkan kinerja serta meminimalisir penggunaan memori dari sistem dapat digunakan memoriflash[9].

Global Positioning System (GPS) merupakan sistem navigasi yang memanfaatkan teknologi satelit untuk menerima sinyal yang berasal dari satelit. Jumlah satelit yang digunakan sistem ini untuk mengirimkan sinyal gelombang mikro ke bumi adalah 24 satelit. Pada penelitian ini, teknologi Lattitude dan Longitude yang dimiliki oleh Global Positioning System (GPS) yang akan digunakan untuk mengetahui titik koordinat pendaki yang mengalami kecelakaan.

Kedua informasi ini berfungsi untuk memberitahu koordinat pendaki melalui GPS U-Blok Neo 6M yang telah terintegrasi pada Transmitter Emergency Button yang dibawa pendaki yang kemudian akan diteruskan ke Relay hingga akhirnya sampaike Receiver.

\section{METODE PENELITIAN}

Berikut di bawah ini merupakan gambar tahapan kerangka penelitian :

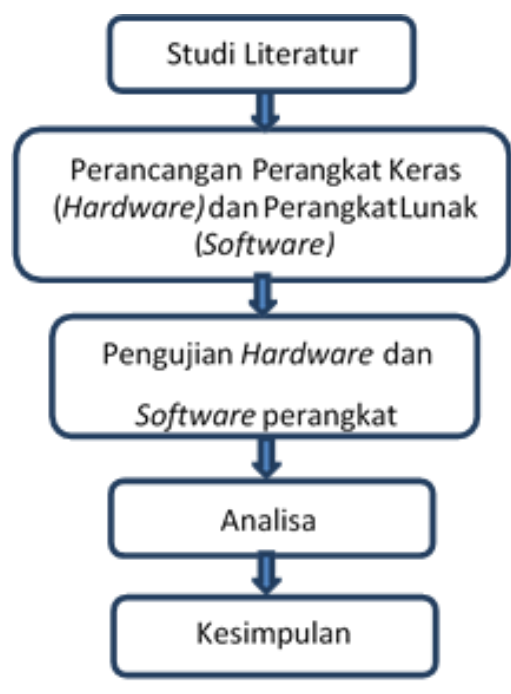

Gambar 4. Tahapan Penelitian 


\section{Perancangan Emergency Buttton Untuk Pendaki Gunung Dengan Sistem Komunikasi Multihop Berbasis LoRa}

Pada tahap perancangan perangkat keras, penulis akan merancang sebuah perangkat yang sesuai dengan kebutuhan dari alat. Pada perancangan perangkat keras ini terdapat 3 perangkat keras yang akan dirancang, yakni Emergency Button yang nantinya akan dibawa oleh pendaki, Relay yang berfungsi jembatan penghubung antara Transmitter dan Receiver agar data yang dikirim oleh Transmitter tidak banyak mengalami loss, dan Receiver yang berada di Pos penjaga sebagai penerima akhir dari data yang dikirimkan. Pada setiap perangkat keras yang ada di pasang antena agar lebih memaksimalkan cakupan sinyal yang dikirim dan diterima. Berikut merupakan blok diagram perancangan perangkat keras :

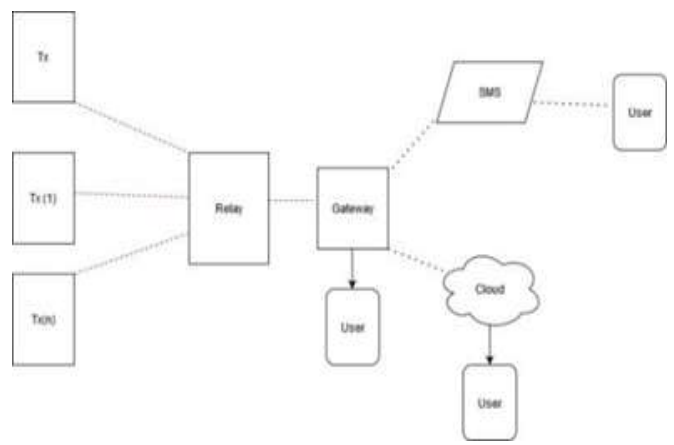

Gambar 5. Perancangan Perangkat

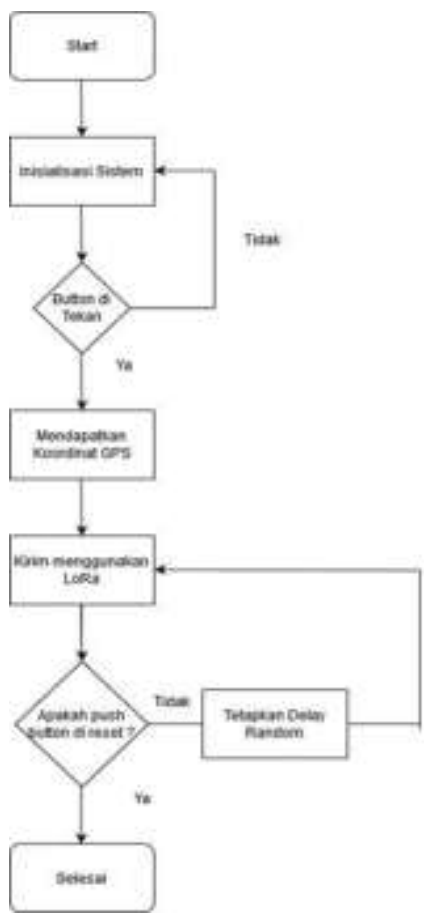

Gambar 6. Diagram perangkat keras Transmitter

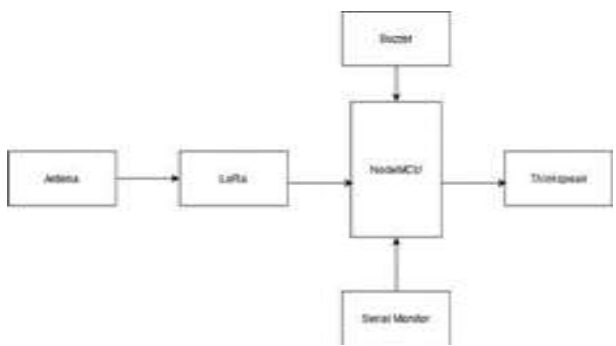

Gambar 7. Diagram perangkat keras Relay

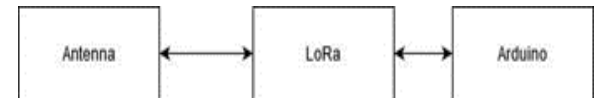

Gambar 8. Diagram perangkat keras Gateway

Sedangkan untuk tahapan perancangan perangkat lunak, penulis menggunakan perangkat lunak Arduino IDE yang digunakan untuk mengatur program yang ingin diinput untuk menjalankan dan mengkoneksikan perangkat keras dan perangkat lunak agar dapat berjalan sesuai dengan semestinya. Berikutdiagram perancangan perangkat lunak:

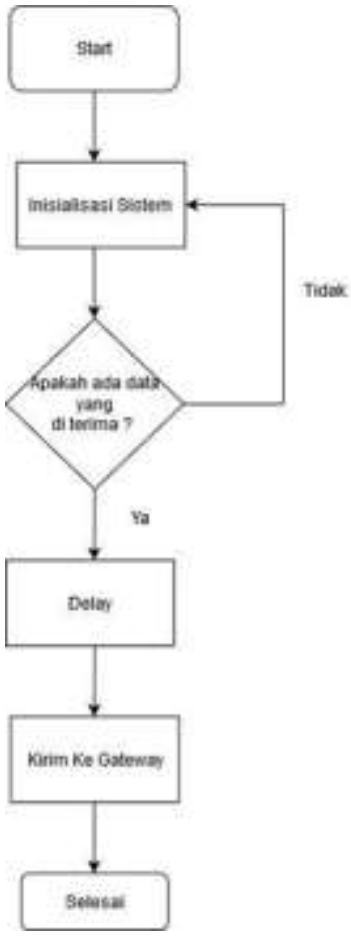

Gambar 9. Diagram Perangkat Lunak

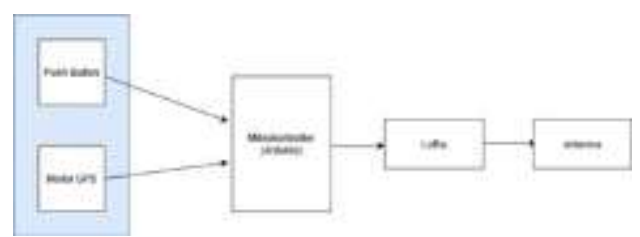

Gambar 10. Diagram perangkat lunak Transmitter

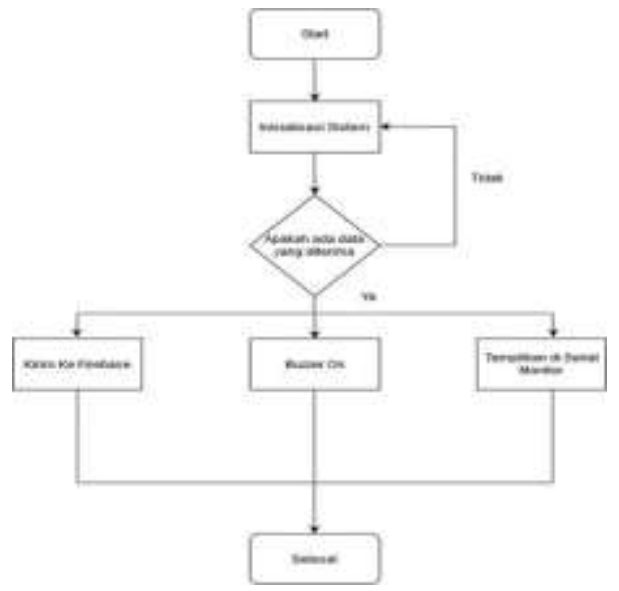

Gambar 11. Diagram perangkat lunak Relay 


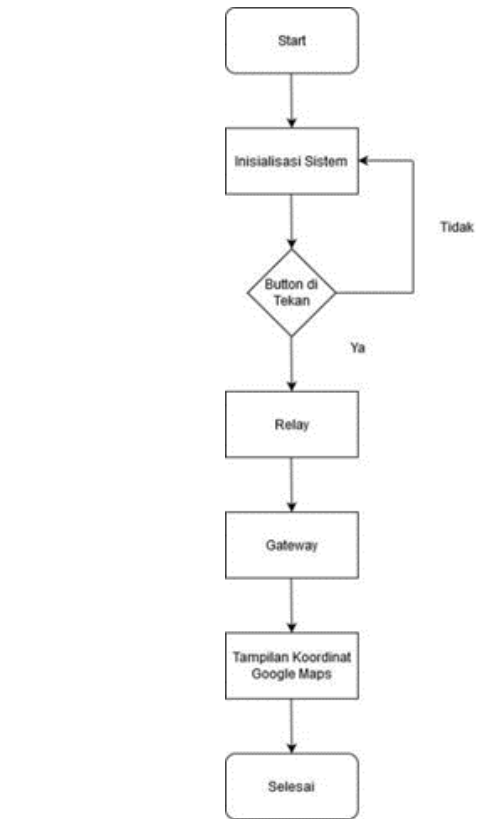

Gambar 12. Diagram perangkat lunak Gateway

\section{HASIL DANPEMBAHASAN}

A. Pengujian Perangkat keras dan PerangkatLunak Pada tahapan ini, penulis melakukan pengujian perangkat keras dan perangkat lunak yang sebelumnya telah ter-integrasi dan ter-connect antara satu sama lain. Pengujian kedua perangkat ini bertujuan untuk melihat bagaimana kinerja kedua perangkat dilapangan dengan mengujikan beberapa parameter sepertiReceived Signal Strength Indicator (RSSI), Signal to Noise Ratio (SNR), Paket loss dan delay. Pada perancangan Emergency Button ini memerlukan beberapa komponenutama yakni :
1. Arduino
2. LoRa
3. GPS Neo 6M
4. NodeMCU EPS8266
5. Bread Broad
6. Buzzer
7. Push Button
8. LCD $16 \times 2$
9. Box Hitam
10. Antenna
11. Kabel Jumper
secukupnya
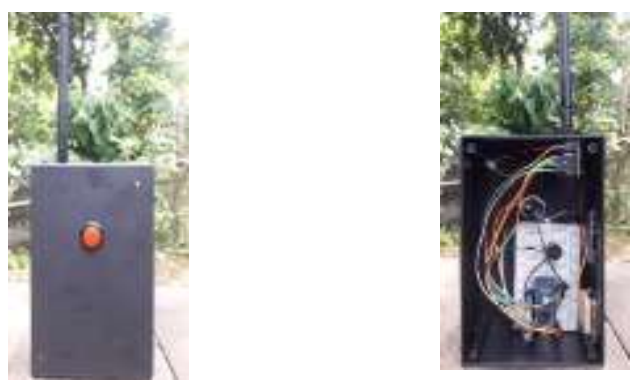

Gambar 13. Tampakdepandan belakang Hardware Transmitter
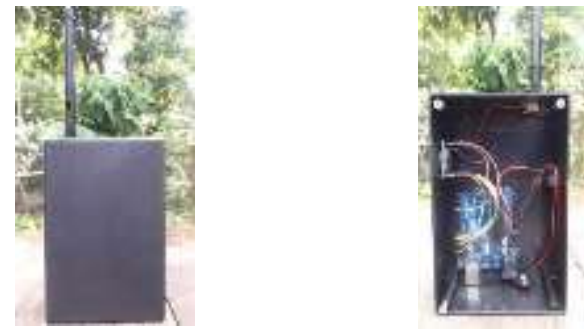

Gambar.14. Tampak depan dan belakang Hardware Relay
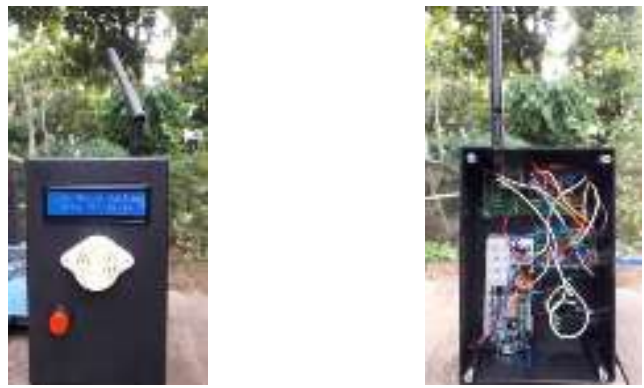

Gambar. 15. Tampakdepandanbelakang Hardware Receiver

B. HasilPengujian di Lapangan

Pada tahapan pengujian penelitian perangkat keras Emergency Button di hubungkan dengan source code yang ada pada aplikasi Arduino di komputer. Pengujan ini dilakukan pada Kamis, 15 juli 2021 pukul 11:00 WIB di Kabupaten Lahat. Berikut merupakan wilayah pengujian alat serta hasil yang didapat setelah dilakukannya pengujian dilapangan:

C. HasilujiPaket Loss antara Transmitterdan Relay

Packet loss merupakan salah satu cara yang dapat dilakukan untuk menguji kualitas link komunikasi karena dari packet loss dapat dilihat banyaknya jumlah paket yang gagal mencapai tujuan pada saat pengiriman paket.

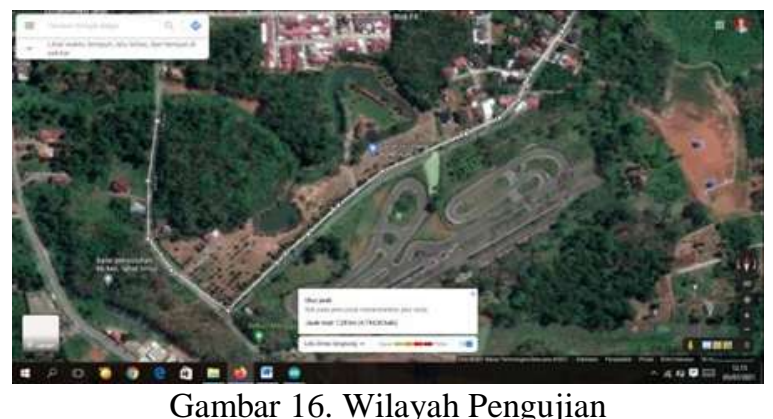

D. Hasil Uji RSSI antara Transmitter dan Relay

Seteleh melakukan pengujian di lapangan didapatlah data RSSI seperti pada tabel 1. Berikut ini: 
Tabel 1. Hasil Uji RSSI

\begin{tabular}{|c|c|c|}
\hline No & $\begin{array}{c}\text { Jarak } \\
(\mathrm{m})\end{array}$ & $\begin{array}{c}\text { Nilai Rerata RSSI Hasil } \\
\text { Pengujian }(\mathrm{dBm})\end{array}$ \\
\hline 1 & $0 \mathrm{~m}$ & -61 \\
\hline 2 & $10 \mathrm{~m}$ & -94 \\
\hline 3 & $200 \mathrm{~m}$ & -117 \\
\hline 4 & $400 \mathrm{~m}$ & -117 \\
\hline 5 & $500 \mathrm{~m}$ & -110 \\
\hline 6 & $600 \mathrm{~m}$ & -118 \\
\hline 7 & $900 \mathrm{~m}$ & Sinyal Loss \\
\hline 8 & $1 \mathrm{~km}$ & Sinyal Loss \\
\hline 9 & $1,2 \mathrm{~km}$ & Sinyal Loss \\
\hline
\end{tabular}

\section{E. HasilujiSNR antara Transmitter dan Relay}

Signal to Noise Ratio (SNR) merupakan rasio yang terjadi antara daya yang diterima dengan tingkat noise. Dalam komunikasi LoRa SNR berkisar antara -20 dB hingga $+10 \mathrm{~dB}$. Berikut merupakan hasil SNR LoRa :

Tabel 2. Hasil Uji SNR :

\begin{tabular}{|c|c|c|}
\hline No & Jarak & Rerata SNR $(\mathrm{dB})$ \\
\hline 1 & $0 \mathrm{~m}$ & 9,6 \\
\hline 2 & $10 \mathrm{~m}$ & 8,5 \\
\hline 3 & $200 \mathrm{~m}$ & $-2,0$ \\
\hline 4 & $400 \mathrm{~m}$ & $-3,35$ \\
\hline 5 & $500 \mathrm{~m}$ & $-6,3$ \\
\hline 6 & $600 \mathrm{~m}$ & $-6,5$ \\
\hline 7 & $900 \mathrm{~m}$ & Sinyal Loss \\
\hline 8 & $1 \mathrm{~km}$ & Sinyal Loss \\
\hline 9 & $1,2 \mathrm{~km}$ & Sinyal Loss \\
\hline
\end{tabular}

Packet Loss juga dapat dihitung menggunakan rumus:

Packet Loss $=\frac{\text { Paket yang dikirim }- \text { Paket yang terima }}{\text { Paket } \text { yang dikirim }} \times 100 \%$

Atau juga dengan perhitungan yang telah diinput di dalam program perangkat lunak pada Arduino IDE.

Tabel 3. Hasil Uji Packet Loss

\begin{tabular}{|c|c|c|}
\hline No & Jarak $(\mathrm{m})$ & Rerata Packet Loss $(\%)$ \\
\hline 1 & 0 & 0 \\
\hline 2 & 10 & 0 \\
\hline 3 & 200 & 19,1 \\
\hline 4 & 400 & 0 \\
\hline 5 & 500 & 0 \\
\hline 6 & 600 & 0,8 \\
\hline 7 & 900 & 0,95 \\
\hline 8 & 1 & 100 \\
\hline 9 & $1,2 \mathrm{Km}$ & 100 \\
\hline
\end{tabular}

F. Hasil uji Delay antara Transmitter dan Relay

Delay merupakan selisih waktu yang terjadi ketika pengiriman dari end node sampai waktu masuk data ke gateway. Berikut merupakan hasil delay dari hasil pengujian alat :

Tabel 4. Hasil Uji Delay

\begin{tabular}{|c|c|c|}
\hline No & Jarak $(\mathrm{m})$ & Rerata Delay $(\mathrm{ms})$ \\
\hline 1 & 0 & 0 \\
\hline 2 & 10 & $901,71 \mathrm{~ms}$ \\
\hline 3 & 200 & $1071 \mathrm{~ms}$ \\
\hline 4 & 400 & $1141 \mathrm{~ms}$ \\
\hline 5 & 500 & $1523 \mathrm{~ms}$ \\
\hline 6 & 600 & $1727,1 \mathrm{~ms}$ \\
\hline 7 & 900 & Sinyal Loss \\
\hline 8 & 1 & Sinyal Loss \\
\hline 9 & $1,2 \mathrm{Km}$ & Sinyal Loss \\
\hline
\end{tabular}

G. Hasil Uji pengiriman data dari Transmitter, Relay dan Receiver

Dilakukannya pengujian ini untuk memastikan bahwa data yang dikirim telah benar-benar sampai di Receiver. Dan data yang diterima oleh receiver, merupakan data yang dikirim oleh Relay. Berikut merupakan tabel pengujiannya :

Tabel 5. Hasil Uji ketiga Alat

\begin{tabular}{|c|c|c|c|}
\hline No & Trnasmitter & Relay & Receiver \\
\hline 1 & $13: 39: 32: 929$ & $13: 29: 32: 999$ & $13: 39: 33: 069$ \\
\hline 2 & $13: 39: 35: 001$ & $13: 39: 35: 041$ & $13: 39: 35: 151$ \\
\hline 3 & $13: 39: 37: 052$ & $13: 39: 37: 122$ & $13: 39: 37: 192$ \\
\hline 4 & $13: 39: 39: 132$ & $13: 39: 39: 162$ & $13: 39: 39: 252$ \\
\hline 5 & $13: 39: 41: 193$ & $13: 39: 41: 213$ & $13: 39: 41: 334$ \\
\hline
\end{tabular}

\section{KESIMPULAN}

Berdasarkan penelitian mengenai Emergency Button bagi pendaki gunung dengan menggunakan sistem komunikasi multihop yang berbasis dengan LoRa dapat ditarik kesimpulan bahwa, penempatan Relay sebagai hop yang berfungsi untuk menambah jarak jangkauan sinyal pada medan pegunungan adalah berada pada kisaran 600 meter. Serta dapat dipastikan bahwa data yang diterima oleh Receiver, merupakan benar data yang dikirm oleh Relay, dan bukan data yang dikirim oleh Transmitter

\section{DAFTAR PUSTAKA}

[1] Prastowo, Fuji Riang., \& Rasyid, A. Harun Al. “ Nasionalisme di Puncak Gunung : Etnografi Komunitas Pemuda Pecinta Alam dalam wacana Ecosophy dan Gerakan Lingkungan di Malang. Jurnal Studi Pemud@, 8(2), 2019..

[2] Aminullaah, Aam. 2019. Kecelakaan Pendakian Gunung di Indonesia Meningkat 4 Thun Terakhir. www.kompas.com diakses pada tanggal 5 Oktober 2019

[3] Semtech. LoRa modulation basics; 2019. https://www.semtech.com/uploads/documents/an 1200.22.pdf

[4] Qing, Lyu., Guangyao, Han., \& Xiaomei, Fu., “ Physical Layer Security in Multihop AF Rela y Network Based on Compressed Sensing”.2018

[5] Peraturan Menteri Komunikasi dan Informatika Republik Indonesia Nomor 1 / Permenkominfo /Tentang Penggunaan Spektrum Frekuensi 
Radio Berdasarkan Izin Kelas. 2019

[6] Rizky, M., Niswar, N., Adnan, fall, Doudou., Kashihiran, S. "Loupe : LoRa Performance Measurement Tool". The 2nd East I ndonesia Conference on Computer and Information Technology. 2018

[7] Bento, Antonio Charlos. "IOT:NodeMCU 12Ex Arduino Uno, Resluts of an experiment and comperative survey". International Journal of Advance Research in Cmputer Science and Management Studies.6,46-56.2018

[8] Hidayanti F, Lestari K,., and Anwar R. "Arduino Based Conductive Silver Lamination Device"/ International Journal of Emerging Trends in Engineering Reseacrh. 265-270.8(2).2020

[9] Srivastava,Prakhar., Bajaj,Mohit., \& Rana, Ankur Singh. "IoT Based Controlling of Hybrid Energy System using ESP8266". 2018

[10] Febriyan, Muhammad Fadhiil, Ibnu Ziad, and Suroso Suroso. "Rancang Bangun Emergency Button Berbasis LORA." PROtek: Jurnal Ilmiah Teknik Elektro 7.2 : 95-98. 2020. 